\title{
Interacting Like Humans? Understanding the Effect of Anthropomorphism on Consumer's Willingness to Pay in Online Auctions
}

\author{
Lingyao (Ivy) Yuan \\ Iowa State University \\ lyuan@iastate.edu
}

\author{
Alan R. Dennis \\ Indiana University \\ ardennis@indiana.edu
}

\begin{abstract}
Most research examining individuals' bidding behavior in online auctions has used the lens of a rational decision making process. However, bidding behavior is also influenced by non-rational factors. Anthropomorphism, attributing human characteristics to a non-human object, has been studied in many disciplines, but has not been investigated in online auctions. This study aims to identify whether auditory and visual design factors for a non-human product would induce anthropomorphism and impact individuals' bidding decision. Results show that visual design induces individuals' anthropomorphism and also impacts bidding decisions.
\end{abstract}

\section{Introduction}

Online auctions have been one of the greatest successes in electronic commerce [12]. eBay, the largest online auction website, currently has more than 100 million active users worldwide. In 2015, more than 82 billion dollars' worth of products were traded on eBay and this number should remain steady in 2016. Online auction are widely used for both new products and the resale of used and collectable items whose value is harder to assess [31]. The rapid growth of auctions, and their popularity makes them an important marketplace that is expected grow $[84,71]$. Understanding the factors that influence consumer behaviors in online auctions, especially bidding behaviors, is thus an issue of both theoretical and practical significance.

Most prior research has used the lens of rational decision making to explain individuals' bidding behavior, reasoning that an individual's decision is based on maximizing benefits $[17,70]$. Several factors affecting consumers' bidding decisions have been identified, including the number of visual cues (e.g., product pictures), the number of bidders, explicit reference points, and previous purchase satisfaction [6, $74,92]$. This research has been built upon an assumption that consumers bid rationally [17].

Other research suggests that auctions include a nonrational component [66]. Bidding decisions are affected both by rational analysis and emotional responses to the product [75]. Individuals' emotional responses can change their behavior such the bidding decisions are not completely rational $[93,65]$. Emotional responses can be influenced through different channels, including visual. Visual cues in the auction environment influence the bidding decision $[6,74,91]$. The graphic design of online auctions can be easily manipulated, compared with traditional auctions. Thus, the online auction provides us a great opportunity to investigate how the auction environment influences bidding behavior.

We investigate the impact of an automatic process, anthropomorphism, and ways to induce this process on individuals in the online auction context. Anthropomorphism, imbuing non-human objects with human form or characteristics, has the potential of changing the interaction pattern and relationship between users and the virtual world [26, 42]. Anthropomorphism is a topic mostly studied in sociology, computer science, and telecommunication for two main purposes, understanding peoples' religious beliefs, and improving human-computer interaction. However, anthropomorphizing products to be more humanlike can be used to change the consumer-product relationship. Thus, this study aims to answer the following research question:

In the online auctions, do design factors that induce anthropomorphism affect bidding behavior?

\section{Theory}

\subsection{Online auctions and individuals' willingness to pay}

Online auctions have become increasingly popular, enabling consumers to purchase goods from both businesses and individual sellers [9]. In this environment, understanding consumers' willingness to pay is important to business success $[8,9]$.

Previous research on rational choice theory shows that bidding behavior is influenced by product information, pricing and the auction system itself [17, 70]. The amount a consumer bids is a function of the consumer's perceived value of the product [69]. In some cases, perceived value is indicated by signals in the marketplace, such as the manufacturer's suggested retail 
price (MSRP) [50]. Many products have a clear MSRP (e.g., cameras, cars, TVs), which serves as one indicator of value, although the actual price a consumer pays may differ from MSRP depending where and how a product is purchased. Some products have no MSRP (e.g., used items, collectibles, and artwork), so determining value is more difficult.

Most prior research on online auctions is based on rational choice theory, which assumes that an individual acts rationally to balance costs against benefits to maximize personal advantage $[17,70]$. Common market factors such as product information, product image, pricing strategy $[80,16]$, and system design has been found to influence individuals' willingness to pay and bidding behavior. Research examining the effects of product reviews on bidding suggests separating perceived value from perceived functional value as a strategy to control the impact of product reviews [49]. It is also found that increasing the quality of an auction business's e-image increases the prices received at the auction and individuals' willingness to transact with the business [32]. Non-contractible elements, including supplier technological investments, information exchange, responsiveness, trust, and flexibility of relationships also have great explanatory power for auction use [52]. Implementing information feedback into the auction system also increases the amount of successful trading on the auction websites because it helps build trust, which is critical in electronic auctions $[1,9]$. Prior research has found that users' online auction addiction has an impact on their reasoned usage decisions by altering their belief systems [82]. Researchers also have looked into perception formation in sequential auctions [28].

Most of the research on electronic auctions has been built on an assumption that consumers make rational decisions. Behaviors resulted from or impact by other factors have not caught the attention or interest of most researchers. Yet individuals possess a limited cognitive capability and are not motivated to expend a lot of cognitive effort all the time [72]. An auction environment provides the consumer with a large amount of information about the competing products, resulting uncertainty in the decision making process [84]. The theory of rationality assumes that individuals have infinite cognitive processing capabilities and can make decisions on assessing all aspects of all alternatives provided, irrationality $[17,70]$. In contrast, other research emphasizes the cognitive constraints of individuals $[60,5]$. Most individuals' decisions are also influenced by a desire to reduce the cost of deliberation [20], which indicates that online auction decisions are often non-rational. However, there is little prior literature on the non-rational aspect of online auction decision-making.
Willingness to pay refers to the maximum price an individual is willing to pay for a given product $[90,54]$. It is set subjectively by individuals [90]. Understanding individuals' willingness to pay is crucial in estimating demand and designing the pricing strategy. In online auctions, it is difficult for sellers to price products when a seller is providing a unique or used product for which the demand is ambiguous. Therefore, willingness to pay, capturing the maximum price a buyer is willing to pay, is critical. On the other hand, the auction context provides researchers the opportunity to capture consumers' willingness to pay and thus to investigate the impact of non-rational factors on consumers' behavior.

\subsection{Overview of anthropomorphism}

Anthropomorphism is defined as the attribution of human form or characteristics to a non-human being [51]. Anthropomorphism is spontaneous, pervasive, and powerful $[33,53,13]$. A frustrated computer user may threaten the machine when it fails to perform as expected. A dog owner easily forgives the pet for making a mess in the living room based on the "guilty" look on its face. Humans are born with the gift of anthropomorphism rather than develop it as a learned skill; humans start to anthropomorphize during infancy and carry it throughout their lifetime [36, 41].

There are three overarching questions regarding anthropomorphism that scholars are trying to answer: 1) Why do humans anthropomorphize; 2) how do humans design objects that are intended to induce anthropomorphism; 3) what are the consequences of anthropomorphizing. Some research suggests humans anthropomorphize to reduce the uncertainty of the unknown [33, 14, 89]. Human knowledge is limited so when attempting to explain the unknown, we apply the most familiar assumptions we have, which is ourselves $[14,89]$. Other research argues that humans anthropomorphize to compensate for the lack of social connections with other humans $[24,25]$.

The second question has long been the focus of computer scientists and engineers interested in humancomputer interaction [26, 23]. Prior research has shown that adding facial features and motion to an object are effective in evoking anthropomorphism. In general, the more an object looks and moves like a human, the more positive the response. However, when an object behaves almost, but not exactly, like natural human beings, a response of revulsion is often triggered, creating an "uncanny valley" in responses. It can be easily found in the movie industry. Another example is "Clippie", the animated paper clip figure Microsoft introduced to provide tips and help users. This design invoked great annoyance from users. 
Designing a product to induce anthropomorphism involves several aspects collectively, including adding human facial features, human sounds/voices, intentionality, imitation behavior, communication [21, 79], and movement [37]. Anthropomorphism is powerful and compelling. A static image can trigger the automatic process of anthropomorphism [58]. However, the facial design of the anthropomorphic object may carry a potential downside effect if the design is associated with an unhelpful agent [85].

Voice, especially voice clarity and voice consistency, have a large impact on anthropomorphism [30]. Individuals treat different voices on the same computer as different actors, but treat the same voice on different computers as the same actor [68]. The fit between physical appearance and voice is also critical in triggering anthropomorphism. Individuals spent more time to process information delivered by virtual agents with human face and humanoid voices than by virtual agents with human face and human voice. They also trust the former less than the latter [30].

Movement is another important factor influencing anthropomorphism. Individuals are more likely to perceive humans and nonhuman objects to possess mental states when the objects moved at speeds similar to the speed of human movement, rather than faster or slower than humans [55]. Synchronizing the voice with the movement of the object also appears to be a key to make individuals pay more attention, be more aroused, and have a better evaluation of the object [68].

The third fundamental question facing researchers is what are the effects of anthropomorphism? We know anthropomorphism has an impact on attitude and behavior [35, 68, 48, 45, 15]. Researchers looked into how individuals perceive and react to a computer, and whether they treat computers as real humans. Researchers found that computer users not only can recognize certain personality traits (dominancesubmissiveness and friendliness-unfriendliness) of the computer, they also favor a computer that exhibits similar personality traits to themselves over ones that exhibit opposite traits [68]. Moreover, users prefer computers that "adapt" to them. The ability to adapt facilitates anthropomorphism and social presence [48]. For instance, dominant people prefer a computer that starts out submissive but then becomes dominant, more than a computer that is consistently dominant [68].

The relationship between a person and a computer influences the attitude of the person to the computer. Individuals evaluate the computer as significantly better when they are told that they are teamed with the computer to work on a task than when they are told that they are working alone using the computer [68]. Individuals also tend to attribute human-like emotions to non-human object when the object is considered as an in-group member [11]. They also ascribe personality attributes to programs [40].

Researchers also looked into how individuals treat non-human agents in the virtual environment. In a mock job interview task, individuals' impression of the interviewers and their emotional state were not different when they were interviewed by a real human versus a virtual agent [4]. The longer someone interacts with a virtual agent, the more likely they are to anthropomorphize it [27]. Individuals perceive more anthropomorphic virtual agents to be more attractive and trustworthy [29]. They are more likely to choose more anthropomorphic virtual agents to represent themselves [59]. Virtual agents made sales channels more persuasive and satisfying [87]. Females were influenced more than males by anthropomorphized agents for products with high hedonic value [87].

Consumer behaviors towards a product is influenced by both their perceptions of the anthropomorphized product brand [3, 63]. Through anthropomorphism, consumers can develop a humanlike social relationship with brand mascot [46], although such a relationship is moderated by individual personality [44]. Consumers will develop more favorable attitudes towards the anthropomorphized brand [3, 63], but an anthropomorphized brand will have a greater decrease in consumer attitude if the brand cannot consistently maintain its positive image [64]. Individual characteristics also impact perceptions of anthropomorphic objects [88].

Individuals are found to apply social attributes to non-human objects, especially computers [56, 70]. For instance, researchers found that individuals trust computers more when male voices are used for technical related subjects and when female voices computer are used for love and relationship topics [57]. Individuals perceive computers displaying flattering comments as more attractive and believable. Such effects are more pronounced when the comments is delivered by an anthropomorphic virtual agent [47]. Anthropomorphism of the computer interface also amplify the positive effect of flattering comments on individuals' evaluation on their performance [47]. Since anthropomorphism is an automatic process, it has been used as a way to induce priming $[15,19]$.

Prior research has argued that anthropomorphism may contribute to the value of a product and a consumer's willingness to pay [35]. Prior research has found that anthropomorphism can account for the personal value of products with different levels of complexity [35].

\subsection{Research hypotheses}


As we discussed above, the graphic design of the product is an important trigger of anthropomorphism. Facial features and motion help evoke anthropomorphism. Likewise, adding human voices can trigger anthropomorphism. Combing two manipulations together on the design of the anthropomorphic product is believed to be stronger than a single manipulation itself [22]. This is because humans are known for having distinguishable visual appearance and communication style from other non-living objects or animals. Thus, a non-human object with both visual and auditory manipulation will be more likely to trigger anthropomorphism from individuals. Thus, we hypothesize that:

H1. Individuals will perceive an object with both visual and auditory manipulations to be more human-like than that with only visual or auditory manipulation.

There are potential two paths for visual and auditory manipulations to influence individuals' willingness to pay: an emotional path and a rational path. Prior research has investigated emotion and anthropomorphism [2], and found no direct impact on emotions when the anthropomorphic products carried a neutral or mild emotion [2]. However, when the anthropomorphic product exhibits strong positive emotion, it can trigger both high positive valance and high arousal [45].

Consumers' willingness to pay reflects their perceived value of the product $[17,70]$. Rational choice theory argues that individuals balance cost against benefits to maximize personal advantage [17, 70]. Factors such as product information, product image, pricing strategy, and system design influence consumers' willingness to pay [81].

When individuals are shopping for a product, the cognition process supporting rational reasoning can be influenced in a variety of ways. The Internet and technology makes a vast amount of information available to consumers. However, humans have limited memory resources and cognition capability $[76,77]$ so information is prioritized in the decision making process [7]. During the information collection stage, individuals will allocate more attention to important information [62]. Thus information that is perceived as important to the decision is more accessible to the decision maker [10]. Therefore, by directing consumers' attention to certain product information, one can influence what information the consumer perceives as important, and thus what information is more accessible when making the purchase decision.

Prior research has shown that individuals tend to pay more attention to human faces than objects [86]. Anthropomorphism is an automatic process, so humans are more likely to perceive anthropomorphic products as similar as humans, and thus, will pay more attention to them than to non-anthropomorphic products. Therefore, information delivered through the anthropomorphic product with human-like facial features, expressions, body movement and verbal communication will receive more attention than information delivered in other ways. If this information emphasizes important functional value provided by the product, this value will become more salient, thus leading the consumer to have a higher willingness to pay for thee anthropomorphic product than a non-anthropomorphic product. Thus:

H2. Individuals are willing to pay more for a product with a) visual and $b$ ) auditory manipulation than a non-anthropomorphic product.

\section{Research Methodology}

This study used a 2 (visual manipulation: with vs. without) $\times 2$ (auditory manipulation: with vs. without) factorial design.

\subsection{Participants}

Two hundred and sixty-six undergraduate students in a large state university business school participated in the experiment. 49 participants who either did not follow the experiment procedure or failed the attention test during the experiment were excluded from the sample, resulting in a sample of $217.59 \%$ of the participants were male. The average age was $19.4(95 \%$ of participants were between 19 to 21 years old). The average GPA of all participants was 3.6. All participants were from an introductory business course.

\subsection{Task}

Participants were led to believe that they were recruited to help test an auction system newly developed by the School of Business. Participants were required to purchase a tablet using a Web-based system. The system provided information about the tablet, including the hardware and software configurations, product dimensions, special features, promotion packages, etc. A text field was activated after the manipulation was delivered for participants to enter a bid amount in dollars. Three were no restrictions on how much the participants could bid on the product. The bidding task lasted about 15-20 minutes depending on the treatment.

\subsection{Treatments}

This 2x2 study had four randomly-assigned between-subject treatments: visual/auditory, novisual/auditory, visual/no-auditory, and no-visual/no- 
auditory (control). For the visual treatments, we manipulated the visual appearance of the tablet through two aspects collectively. First, by adding human physical characteristics including eyes, mouth, hands, and feet. Second, the tablet was designed to have human-like movements, such as waving, clapping, jumping, turning, etc. A pilot study was conducted to select the best visual manipulation. The manipulation was delivered as a full motion video. See Figure 1 for an example. For the no-visual manipulation, a product slide show was presented to the subject, also in a video format. The slide show presented different still images of the tablet. See Figure 2.

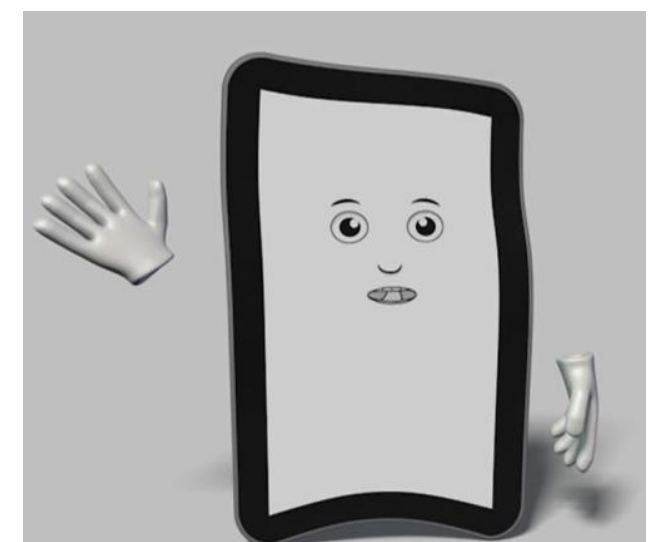

Figure 1. Graphic design of tablet in anthropomorphic condition

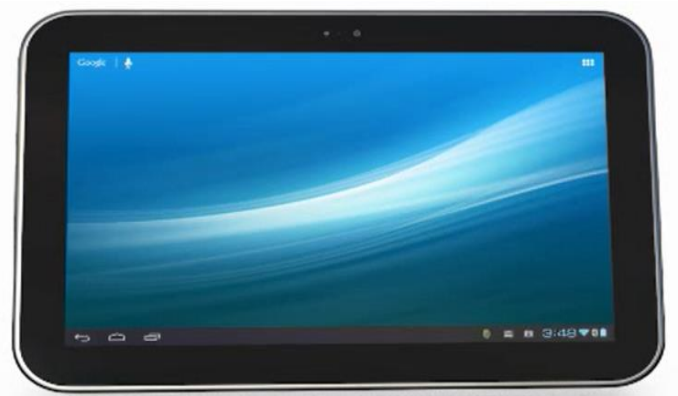

Figure 2. Graphic design of tablet in control condition

For the auditory manipulation, a human voice was recorded by a professional male voice actor following a written script. The voices in the auditory manipulation treatments were recorded as a first person to have direct communication with the viewers. A pilot study was conducted to select the best voice design. For the noauditory manipulation, the script was presented in text subtitles below video.

A question arises as to the best control treatment: should it be a traditional static web page similar to those on commercial auction sites, or should it be the no- visual manipulation slide show video with the no-audio manipulation sub-titles? We conducted a pilot study comparing both options and found no significant differences in individuals' bidding behavior between the two. Therefore, we chose to use the traditional static web page commonly found on commercial auction sites as the control treatment.

\subsection{Dependent variables}

Willingness to pay refers to the dollar amount an individual would pay in order to obtain possession of a product. It was measured right after the participants received all the product information. Perceived Anthropomorphism was measured using the following 3 items (Crobach's alpha $=0.885$ ): 1) How human realistic do you think the product was; 2) How much do you agree/disagree with the following statement $-\mathrm{I}$ felt like I was interacting with a human during bidding for the product; 3) How much do you agree/disagree with the following statement - I don't think the tablet I bid on looks like a real person.

\subsection{Control variables}

Two control variables, product knowledge and gender, were measured during the experiment. Product knowledge has been found to impact consumer behavior in marketing literature [67, 73, 61]. Gender has been shown to have an effect on individual decision making $[43,83]$.

\subsection{Procedures}

Data was collected in a computer lab in the business school. Participants were given instructions on the bidding task and the online bidding website. Each participant was randomly assigned to one of the four treatments. The time for the bidding task ranged from 15 to 20 minutes. The bid was captured during the bidding task automatically by the bidding website. After finishing the bidding task, participants were asked to complete an online survey, which measured demographic variables, control variables and an attention check to filter out any participants who did not complete the study seriously.

\section{Results}

Univariate Analysis of Variance was conducted using SPSS 22 to test the impact of visual manipulation and audio manipulation on perceived anthropomorphism. The results (see Tables 1 and 2) 
show that the visual manipulation significantly increased individuals' perceived anthropomorphism $(\mathrm{F}(1,213)=12.68, \mathrm{p}<0.000)$. However, the auditory manipulation had no impact $(\mathrm{F}(1,213)=0.09, \mathrm{p}=0.765)$. There was no significant interaction effect $(\mathrm{F}(1,213)$ $=0.05, \mathrm{p}=0.826)$. H1 was not supported.

\section{Table 1. Descriptive statistics for perceived anthropomorphism}

\begin{tabular}{|l|l|l|l|l|}
\hline \multicolumn{2}{|c|}{ Manipulation } & \multicolumn{1}{c|}{$\mathbf{n}$} & Mean & SD \\
\hline \multirow{3}{*}{ Visual } & Yes & 120 & 2.54 & .14 \\
\cline { 2 - 5 } & No & 97 & 1.78 & .15 \\
\hline \multirow{2}{*}{ Auditory } & Yes & 127 & 2.18 & .13 \\
\cline { 2 - 5 } & No & 90 & 2.15 & .15 \\
\hline
\end{tabular}

Table 2. Results for perceived anthropomorphism

\begin{tabular}{|c|c|c|}
\hline Manipulation & F & p-value \\
\hline Visual & 12.68 & .000 \\
\hline Auditory & 0.09 & .765 \\
\hline Interaction & 0.05 & .826 \\
\hline
\end{tabular}

The results for the willingness to pay indicated a significant main effect for the visual manipulation (see Tables 3 and 4). Participants who interacted with the human-like visual design, were willing to pay $\$ 31.45$ (about 11\%) more for the tablet. No significant main effect was found for the auditory manipulation or the interaction. Of the two control variables, gender was found to significantly impact participants' bids $(\mathrm{F}(1$, 213) $=9.708, p=0.002$ ), while no effect was found for product knowledge $(\mathrm{F}(1,213)=0.050, \mathrm{p}=0.823)$. Therefore, $\mathrm{H} 2 \mathrm{a}$ is supported but $\mathrm{H} 2 \mathrm{~b}$ is not.

Table 3. Descriptive statistics for amount bid

\begin{tabular}{|l|l|l|l|l|}
\hline \multicolumn{2}{|c|}{ Manipulation } & \multicolumn{1}{c|}{ n } & Mean & \multicolumn{1}{c|}{ SD } \\
\hline \multirow{2}{*}{ Visual } & Yes & 120 & 314.31 & 100.92 \\
\cline { 2 - 5 } & No & 97 & 282.86 & 99.03 \\
\hline \multirow{2}{*}{ Auditory } & Yes & 127 & 303.06 & 110.28 \\
\cline { 2 - 5 } & No & 90 & 296.28 & 86.88 \\
\hline
\end{tabular}

Table 4. Results for amount bid

\begin{tabular}{|c|c|c|}
\hline Manipulation & F & p-value \\
\hline Visual & 5.34 & .022 \\
\hline Auditory & 0.04 & .835 \\
\hline Interaction & 0.60 & .439 \\
\hline
\end{tabular}

\section{Discussion}

\subsection{Interpretation of findings}

Results of this study shows that visual manipulation of a non-human object by adding human facial features and limbs induces anthropomorphism and causes consumers to bid more. No effects were found due to the auditory manipulation, nor was the interaction of visual and auditory manipulation. Adding human facial features and gestures to a non-human object has a stronger impact in making individuals imagine and treat the object as a real human compared with adding voices to the object.

Our hypotheses were not fully supported by the findings; the visual manipulation mattered but the auditory manipulation did not. In some ways, this is a glass half full result. The visual design has been proven to play a critical factor. Attaching a voice to the product did not influence anthropomorphism or the amount bid in our study; however it does not mean that designers of auction sites should not focus on voices design of the product. Our results indicates that a better voice design should be tested.

There are several possible explanations for this result. The first is that the auditory manipulation is not strong enough to induce anthropomorphism. According to prior research, anthropomorphism and other subconscious processes can be influenced by many different factors simultaneously [34, 53]. Manipulating one aspect of the design may or may not trigger several mental mechanisms. Thus, it requires great precision in designing the manipulation. It requires further research to identify the best manipulation to the auditory manipulation.

Another explanation for this is the fit between the subjects' expectations of the product and the manipulation. Specifically, participants may have different expectations about the voice. Some participants may expect a tablet to have a female voice, because Apple products such as Siri use female voices. The auditory manipulation using a male voice may create a discrepancy between expectations and the manipulation, reducing the impact of the manipulation.

A third possible explanation is that people are more used to seeing visual manipulations than hearing a voice attached to the product. Thus, they are more critical towards the voice, making it harder for the manipulation to take effect.

\subsection{Theoretical contributions}

The results of this study have the potential to make several contributions to research. First, we believe this study opens a new door in online auction research and electronic commerce research in general. Prior studies have examined "rational" factors affecting individuals' willingness to pay under the assumption of rational choice theory. These factors are important. However, 
we need to look beyond the straightjacket of rational choice [78, 39, 38]. This study investigates the impact of one of the many automatic processes, anthropomorphism, and thus starts to reveal the impact of non-rational processes on individuals' behavior.

Second, the study of anthropomorphism as a research area is relatively new to the IS discipline. Online auctions and other forms of e-commerce involve complicated cognitive and emotional processes. This study can inform future studies examining anthropomorphism. However, measuring anthropomorphism can be difficult and more complex. This research is just one step in the processing of refining our understanding of anthropomorphism and its impact on human-computer interaction.

Third, the study provides insight into what types of manipulations affect bidding behavior. Visual manipulation of anthropomorphism leads individuals to be willing to pay more for a product while auditory manipulation has no impact. More research is needed to understand how product design, especially visual design affects anthropomorphism.

\subsection{Implications for practice}

The findings of this research can be applied to electronic commerce. First, for companies using online auctions, anthropomorphizing products using visual design can be a powerful way to increase revenue because consumers may be willing to pay more for anthropomorphic products. However, spending money on professional voice talent to attach a voice to the product may be less likely to influence the amount bid.

Second, our research suggests that consumers should be mindful while watching or interacting with product designed to induce anthropomorphism. It is possible for consumers to over-pay for a product with a human like face, body features, and movements. It would also benefit the industry if researchers can investigate the impact of design choices; for instance, using a female voice instead of a male voice may lead to different bidding behavior from consumers.

\subsection{Limitations and future research}

One potential limitation of the study is that the sample was limited to undergraduate students. Student samples are appropriate for testing theories about phenomena theorized to hold across the population as a whole [18]. Young adults in the same age range as the participants in our study are active online consumers. However, it is possible that the effects of anthropomorphism may vary across age groups.
Another limitation of this study is that lab experiment was used as research method. An artificial online bidding website was developed for data collection purposes. The website is different from online bidding websites in real life in that participants could only view and bid on one product. The artificial design nature of the data collection tool may pose a threat to the validity of the results.

A third limitation is that the animation of the product. The results of the pilot study indicated that business students were more attracted to cartoon-like designs. However, such design makes the product look less real. Last but not the least, the effect size for this study is comparatively low. In order to validate the results, further examination on the hypothesized relationships should be conducted.

\section{References}

[1] G. Adomavicius, S. P. Curley, A. Gupta and P. Sanyal, "Impact of Information Feedback in Continuous Combinatorial Auctions: An Experimental Study of Economic Performance", Management Information Systems Quarterly, 37 (2013), pp. 55-76.

[2] P. Aggarwal and A. L. McGill, "Is that car smiling at me? Schema congruity as a basis for evaluating anthropomorphized products", Journal of Consumer Research, 34 (2007), pp. 468-479.

[3] P. Aggarwal and A. L. Mcgill, "When Brands Seem Human, Do Humans Act Like Brands? Automatic Behavioral Priming Effects of Brand Anthropomorphism", Journal of Consumer Research, 39 (2012), pp. 307-323.

[4] E. Aharoni and A. J. Fridlund, "Social reactions toward people vs. computers: How mere lables shape interactions", Computers in human behavior, 23 (2007), pp. 2175-2189.

[5] D. Ariely and S. Jones, Predictably irrational, HarperCollins New York, 2008.

[6] D. Ariely and I. Simonson, "Buying, bidding, playing, or competing? Value assessment and decision dynamics in online auctions", Journal of Consumer psychology, 13 (2003), pp. 113-123.

[7] A. D. Baddeley, Human memory: Theory and practice, Psychology Press, 1997.

[8] W. L. Baker, E. Lin, M. V. Marn and C. C. Zawada, "Getting prices right on the web", McKinsey Quarterly (2001), pp. 54-63.

[9] R. Bapna, P. Goes and A. Gupta, "Analysis and design of business-to-consumer online auctions", Management Science, 49 (2003), pp. 85-101. 
[10] J. A. Bargh and R. D. Thein, "Individual construct accessibility, person memory, and the recall-judgment link: The case of information overload", Journal of Personality and Social Psychology, 49 (1985), pp. 1129.

[11] A. Besmann and K. Rios, "Pals in power armor: Attribution of human-like emotions to video game characters in an ingroup/outgroup situation", Cyberpsychology, Behavior, and Social Networking, 15 (2012), pp. 441-443.

[12] S. Borle, P. Boatwright and J. B. Kadane, "The timing of bid placement and extent of multiple bidding: An empirical investigation using eBay online auctions", Statistical Science (2006), pp. 194-205.

[13] G. M. Burghardt, "Amending Tinbergen: A fifth aim for ethology", (1997).

[14] L. R. Caporael and C. M. Heyes, "Why anthropomorphize? Folk psychology and other stories", Anthropomorphism, anecdotes, and animals (1997), pp. 5973.

[15] T. L. Chartrand, G. M. Fitzsimons and G. J. Fitzsimons, "Automatic effects of anthropomorphized objects on behavior", Social Cognition, 26 (2008), pp. 198-209.

[16] X. Chen, A. Ghate and A. Tripathi, "Dynamic lot-sizing in sequential online retail auctions", European Journal of Operational Research, 215 (2011), pp. 257-267.

[17] J. S. Coleman and T. J. Fararo, Rational choice theory, Sage Publ., 1993.

[18] D. Compeau, B. Marcolin, H. Kelley and C. Higgins, "Generalizability of information systems research using student subjects - a reflection on our practices and recommendations for future research", Information Systems Research, 23 (2012), pp. 1093-1109.

[19] J. A. Cote, "Pets as means rather than ends", Journal of business research, 61 (2008), pp. 500-501.

[20] E. Dane and M. G. Pratt, "Exploring intuition and its role in managerial decision making", Academy of Management Review, 32 (2007), pp. 33-54.

[21] D. C. Dennett, Kinds of minds: Toward an understanding of consciousness, Basic Books, 2008.

[22] B. R. Duffy, "Anthropomorphism and the social robot", Robotics and autonomous systems, 42 (2003), pp. 177-190.

[23] P. Ekman, Darwin and facial expression: A century of research in review, http://www. ishkbooks. com/mal, 2006.

[24] N. Epley, S. Akalis, A. Waytz and J. T. Cacioppo, "Creating social connection through inferential reproduction loneliness and perceived agency in gadgets, gods, and greyhounds", Psychological science, 19 (2008), pp. 114-120.
[25] N. Epley, A. Waytz, S. Akalis and J. T. Cacioppo, "When we need a human: Motivational determinants of anthropomorphism", Social Cognition, 26 (2008), pp. 143155 .

[26] N. Epley, A. Waytz and J. T. Cacioppo, "On seeing human: a three-factor theory of anthropomorphism", Psychological review, 114 (2007), pp. 864.

[27] S. R. Fussell, S. Kiesler, L. D. Setlock and V. Yew, How people anthropomorphize robots, Proceedings of the $3 \mathrm{rd}$ ACM/IEEE international conference on Human robot interaction, ACM, 2008, pp. 145-152.

[28] P. B. Goes, G. G. Karuga and A. K. Tripathi, "Understanding willingness-to-pay formation of repeat bidders in sequential online auctions", Information Systems Research, 21 (2010), pp. 907-924.

[29] L. Gong, "How social is social responses to computers? The function of the degree of anthropomorphism in computer representations", Computers in Human Behavior, 24 (2008), pp. 1494-1509.

[30] L. Gong and C. Nass, "When a Talking-Face Computer Agent is Half-Human and Half-Humanoid: Human Identity and Consistency Preference", Human communication research, 33 (2007), pp. 163-193.

[31] R. D. Gopal, B. Pathak, A. K. Tripathi and F. Yin, "From Fatwallet to eBay: An investigation of online dealforums and sales promotions", Journal of Retailing, 82 (2006), pp. 155-164.

[32] D. G. Gregg and S. Walczak, "Dressing your online auction business for success: An experiment comparing two eBay businesses", MIS Quarterly, 32 (2008), pp. 653-670.

[33] S. Guthrie, Faces in the Clouds, Oxford University Press, 1993.

[34] S. Guthrie, Faces in the Clouds, Oxford University Press, 2015.

[35] P. M. Hart, S. R. Jones and M. B. Royne, "The human lens: How anthropomorphic reasoning varies by product complexity and enhances personal value", Journal of Marketing Management, 29 (2013), pp. 105-121.

[36] G. Hatano and K. Inagaki, "Young children's naive theory of biology", Cognition, 50 (1994), pp. 171-188.

[37] F. Heider and M. Simmel, "An experimental study of apparent behavior", The American Journal of Psychology, 57 (1944), pp. 243-259.

[38] S. Y. Ho, "The attraction of internet personalization to web users", Electronic Markets, 16 (2006), pp. 41-50.

[39] S. Y. Ho and S. H. Kwok, "The attraction of personalized service for users in mobile commerce: an 
empirical study", ACM SIGecom Exchanges, 3 (2002), pp. 10-18.

[40] T. Holtgraves, S. Ross, C. Weywadt and T. Han, "Perceiving artificial social agents", Computers in human behavior, 23 (2007), pp. 2163-2174.

[41] K. Inagaki and K. Sugiyama, "Attributing human characteristics: Developmental changes in over-and underattribution", Cognitive Development, 3 (1988), pp. 5570.

[42] M.-W. Inc., Merriam-Webster's collegiate dictionary, Merriam-Webster, 2004.

[43] J. E. Johnson and P. L. Powell, "Decision making, risk and gender: Are managers different?", British Journal of Management, 5 (1994), pp. 123-138.

[44] S. Kim and A. L. McGill, "Gaming with Mr. Slot or gaming the slot machine? Power, anthropomorphism, and risk perception", Journal of Consumer Research, 38 (2011), pp. 94-107.

[45] J. R. Landwehr, A. L. McGill and A. Herrmann, "It's got the look: The effect of friendly and aggressive "facial" expressions on product liking and sales", Journal of marketing, 75 (2011), pp. 132-146.

[46] C. D. Lanier Jr, C. S. Rader and A. R. Fowler III, "Anthropomorphism, marketing relationships, and consumption worth in the Toy Story trilogy1", Journal of Marketing Management, 29 (2013), pp. 26-47.

[47] E.-J. Lee, "What triggers social responses to flattering computers? Experimental tests of anthropomorphism and mindlessness explanations", Communication Research, 37 (2010), pp. 191-214.

[48] K. M. Lee, N. Park and H. Song, "Can a robot be perceived as a developing creature?", Human communication research, 31 (2005), pp. 538-563.

[49] X. Li and L. M. Hitt, "Price effects in online product reviews: an analytical model and empirical analysis", MIS Quarterly, 34 (2010), pp. 809-832.

[50] S. Menon and B. E. Kahn, "The impact of context on variety seeking in product choices", Journal of Consumer Research (1995), pp. 285-295.

[51] I. Merriam-Webster, Webster's ninth new collegiate dictionary, Merriam-Webster, 1983.

[52] S. Mithas, J. L. Jones and W. Mitchell, "Buyer intention to use internet-enabled reverse auctions: the role of asset specificity, product specialization, and non-contractibility", MIS quarterly, 32 (2008), pp. 705-724.

[53] S. Mithen and P. Boyer, Anthropomorphism and the evolution of cognition, JSTOR, 1996.
[54] B. Moldovanu and M. Tietzel, "Goethe's second-price auction", Journal of Political Economy, 106 (1998), pp. 854859.

[55] C. K. Morewedge, J. Preston and D. M. Wegner, "Timescale bias in the attribution of mind", Journal of Personality and Social Psychology, 93 (2007), pp. 1.

[56] C. Nass, B. Fogg and Y. Moon, "Can computers be teammates?", International Journal of Human-Computer Studies, 45 (1996), pp. 669-678.

[57] C. Nass, Y. Moon and N. Green, "Are Machines Gender Neutral? Gender-Stereotypic Responses to Computers With Voices", Journal of Applied Social Psychology, 27 (1997), pp. 864-876.

[58] K. L. Nowak, M. A. Hamilton and C. C. Hammond, "The effect of image features on judgments of homophily, credibility, and intention to use as avatars in future interactions", Media Psychology, 12 (2009), pp. 50-76.

[59] K. L. Nowak and C. Rauh, "The influence of the avatar on online perceptions of anthropomorphism, androgyny, credibility, homophily, and attraction", Journal of ComputerMediated Communication, 11 (2005), pp. 153-178.

[60] L. Ordonez and L. Benson III, "Decisions under time pressure: How time constraint affects risky decision making", Organizational Behavior and Human Decision Processes, 71 (1997), pp. 121-140.

[61] J. P. Peter, J. C. Olson and K. G. Grunert, Consumer behavior and marketing strategy, McGraw-Hill London, 1999.

[62] J. E. Plaks, S. J. Stroessner, C. S. Dweck and J. W. Sherman, "Person theories and attention allocation: preferences for stereotypic versus counterstereotypic information", Journal of Personality and Social Psychology, 80 (2001), pp. 876.

[63] M. Puzakova, H. Kwak and J. F. Rocereto, "Pushing the envelope of brand and personality: antecedents and moderators of anthropomorphized brands", Advances in Consumer Research, 36 (2009), pp. 413-420.

[64] M. Puzakova, H. Kwak and J. F. Rocereto, "When humanizing brands goes wrong: the detrimental effect of brand anthropomorphization amid product wrongdoings", Journal of marketing, 77 (2013), pp. 81-100.

[65] C. Qiu and C. W. Yeung, "Mood and comparative judgment: Does mood influence everything and finally nothing?", Journal of Consumer Research, 34 (2008), pp. 657-669.

[66] A. Quemin and C. W. Smith, Auctions. The Social Construction of Value, Annales. Histoire, Sciences Sociales, JSTOR, 1993, pp. 1641-1645. 
[67] A. R. Rao and K. B. Monroe, "The moderating effect of prior knowledge on cue utilization in product evaluations", Journal of Consumer Research (1988), pp. 253-264.

[68] B. Reeves and C. Nass, "The Media Equation: How People Treat Computers, Television,? New Media Like Real People? Places", Computers \& Mathematics with Applications, 33 (1997), pp. 128-128.

[69] S. Rosen, "Hedonic prices and implicit markets: product differentiation in pure competition", The journal of political economy (1974), pp. 34-55.

[70] J. Scott, "Rational choice theory", Understanding contemporary society: Theories of the present (2000), pp. 126-138.

[71] M. Seo, "Online Auctions Become More Competitive", (2013).

[72] H. A. Simon, "A behavioral model of rational choice", The quarterly journal of economics, 69 (1955), pp. 99-118.

[73] M. R. Solomon, D. W. Dahl, K. White, J. L. Zaichkowsky and R. Polegato, Consumer behavior: buying, having, and being, Prentice Hall Upper Saddle River, NJ, 2014.

[74] B. B. Stern and M. R. Stafford, "Individual and social determinants of winning bids in online auctions", Journal of Consumer Behaviour, 5 (2006), pp. 43-55.

[75] J. C. Sweeney and G. N. Soutar, "Consumer perceived value: The development of a multiple item scale", Journal of retailing, 77 (2001), pp. 203-220.

[76] J. Sweller, "Cognitive load during problem solving: Effects on learning", Cognitive science, 12 (1988), pp. 257285.

[77] J. Sweller, "Cognitive load theory, learning difficulty, and instructional design", Learning and instruction, 4 (1994), pp. 295-312.

[78] K. Y. Tam and S. Y. Ho, "Understanding the impact of web personalization on user information processing and decision outcomes", MIS Quarterly (2006), pp. 865-890.

[79] P. D. Tremoulet and J. Feldman, "Perception of animacy from the motion of a single object", PERCEPTIONLONDON-, 29 (2000), pp. 943-952.

[80] A. K. Tripathi, S. K. Nair and G. G. Karuga, "Optimal lot sizing policies for sequential online auctions", Knowledge and Data Engineering, IEEE Transactions on, 21 (2009), pp. 554-567.

[81] E. Turban, "Auctions and bidding on the Internet: An assessment", Electronic Markets, 7 (1997), pp. 7-11.

[82] O. Turel, A. Serenko and P. Giles, "Integrating technology addiction and use: An empirical investigation of online auction users", MIS Quarterly, 35 (2011), pp. 10431061.

[83] V. Venkatesh, M. G. Morris and P. L. Ackerman, "A longitudinal field investigation of gender differences in individual technology adoption decision-making processes", Organizational behavior and human decision processes, 83 (2000), pp. 33-60.

[84] A. Vishwanath, "An empirical investigation into the use of heuristics and information cues by bidders in online auctions", Electronic Markets, 14 (2004), pp. 178-185.

[85] H. C. V. Vugt, J. N. Bailenson, J. F. Hoorn and E. A. Konijn, "Effects of facial similarity on user responses to embodied agents", ACM Transactions on Computer-Human Interaction (TOCHI), 17 (2010), pp. 7.

[86] P. Vuilleumier, J. L. Armony, J. Driver and R. J. Dolan, "Effects of attention and emotion on face processing in the human brain: an event-related fMRI study", Neuron, 30 (2001), pp. 829-841.

[87] L. C. Wang, J. Baker, J. A. Wagner and K. Wakefield, "Can a retail web site be social?", Journal of marketing, 71 (2007), pp. 143-157.

[88] A. Waytz, J. Cacioppo and N. Epley, "Who sees human? The stability and importance of individual differences in anthropomorphism", Perspectives on Psychological Science, 5 (2010), pp. 219-232.

[89] A. Waytz, C. K. Morewedge, N. Epley, G. Monteleone, J.-H. Gao and J. T. Cacioppo, "Making sense by making sentient: effectance motivation increases anthropomorphism", Journal of Personality and Social Psychology, 99 (2010), pp. 410.

[90] K. Wertenbroch and B. Skiera, "Measuring consumers' willingness to pay at the point of purchase", Journal of Marketing Research, 39 (2002), pp. 228-241.

[91] C.-H. Yen and H.-P. Lu, "Effects of e-service quality on loyalty intention: an empirical study in online auction", Managing Service Quality: An International Journal, 18 (2008), pp. 127-146.

[92] C.-H. Yen and H.-P. Lu, "Factors influencing online auction repurchase intention", Internet Research, 18 (2008), pp. 7-25.

[93] L. I. Yuan and A. R. Dennis, The Happiness Premium: The Impact of Emotion on Individuals' Willingness to Pay in Online Auctions, 2014 47th Hawaii International Conference on System Sciences, IEEE, 2014, pp. 3120-3128. 